\title{
Lead Exposure and Liver Function Parameters in Iraqi Workers
}

\author{
Kahtan Ahmed Al-Mzaien, Meena Mohammed Abdul-Hussein*, Jafar Ihsan Hussein, \\ Ahmed Abdul-Qadir, Sufian Abdul-Rahman, Hussam-Aldeen Sami
}

Medical Laboratory Technique, Dijlah University College, Baghdad, Iraq

Email address:

Meena.mhd@duc.edu.iq (M. M. Abdul-Hussein)

${ }^{*}$ Corresponding author

\section{To cite this article:}

Kahtan Ahmed Al-Mzaien, Meena Mohammed Abdul-Hussein, Jafar Ihsan Hussein, Ahmed Abdul-Qadir, Sufian Abdul-Rahman, HussamAldeen Sami. Lead Exposure and Liver Function Parameters in Iraqi Workers. American Journal of Biological and Environmental Statistics. Vol. 5, No. 3, 2019, pp. 42-45. doi: 10.11648/j.ajbes.20190503.12

Received: June 14, 2019; Accepted: August 28, 2019; Published: September 16, 2019

\begin{abstract}
This study was conducted to evaluate the incidence of long term exposure to lead in some biomarkers of liver functions of Iraqi workers. A total ninety -two (92) adult Iraqi workers with a mean ages ( $37 \pm 1.107$ years) were distributed as follows; twenty eight (28) gasoline filling station workers, thirty one (31) battery workers and thirty three (33) brick manufacturing industry workers as well as, eighteen (18) control subjects were not in any way occupationally exposed to lead were involved in this study. The lead level was measured using atomic absorption spectrophotometer method. The blood lead level (BLL) among gasoline station, battery and brick kiln workers were $(24.96 \pm 0.76,24.7 \pm 0.77$ and $24.63 \pm 0.81 \mu \mathrm{g} / \mathrm{dL}$, respectively), and the corresponding values for the control group was significantly $(\mathrm{p}<0.001)$ lower $(18.88 \pm 0.51 \mu \mathrm{g} / \mathrm{dL}$ ). Significant $(\mathrm{p}<0.05)$ elevation in serum alanine transaminase (ALT) activity in gasoline filling station workers, battery manufacture and brick kiln workers among the control group was recorded, while no significant change in serum aspartate transaminase (AST) of all workers versus control was observed. Moreover, significant $(p<0.01)$ increase in alkaline phosphatase activity in the serum of all workers as compared to the control group was recorded. On the other hand, no significant change was listed in albumin and bilirubin in all lead exposed groups. It can be concluded that occupational exposure to lead in Iraq is associated with significant increase of lead level, increased prevalence of lead toxicity and liver dysfunction.
\end{abstract}

Keywords: Component, Occupational Exposure, Blood Lead Level, Biochemical Parameters, Gasoline Station, Battery, Brick Kiln Workers

\section{Introduction}

Lead is one of the oldest chemical toxins, heavy, bluishgray metal and harmful environmental pollutants. Although, Lead is one of the most useful industrial elements, but no benefit function in the human body [1]. The production of batteries that contain lead in automobile industries represent the largest industrial used of lead. Water pipes materials of solder and materials in acid resistant that used in the building industry represent other uses of lead [2]. Lead Poisoning can interfere with many biochemical and metabolic processes in the body and as a result adverse effects occur in multiple organ systems [3]. Measuring of lead levels in blood remains the predominant biological marker in workplace monitoring, clinical assessment, and regulatory authority decisions regarding removal from exposure [4]. The liver is a largest gland and vital organ in the human body which is involved in detoxification and excretion of metabolites, glycogenesis, and albumin production and coagulation factors. Occupational exposure to lead has been associated with oxidative stress in liver tissue and abnormal liver function [5]. Hepatic enzymes and total bilirubin, as Liver function test help to assess the status of the liver [6]. Objective of this study is to determine blood lead level in workers that exposed to lead in Iraq and to assess some biochemical parameters related to lead poisoning and liver function test. 


\section{Materials and Methods}

\subsection{Study Design}

This study was carried out among Iraqis worker in Baghdad city, in the period between January 2019 and March 2019. Ninety two (92) apparently healthy adult males with age range 19-59years were recruited for the study. Twenty eight (28) male works in gasoline filling stations with age range (24-58 years), 31 battery worker male with age range (34-55 years), 33 brick kiln manufacturing industry worker with age range (19-57 years). Conversely eighteen individual's with age of (21-45 years) from general population who almost have no history of being worked at gas stations and matching the experimental group in age and sex were enrolled as a control group. Ten milliliter of venous blood was taken from each participant and immediately transferred into 2 tubes, $3 \mathrm{ml}$ in a tube containing potassium EDTA anticoagulant and $7 \mathrm{ml}$ in a plain tube for serum preparation. The EDTA blood sample were used for the determination of lead levels by graphic furnace atomic absorption spectroscopy by dilution $2.5 \mathrm{ml}$ of whole blood in $2.5 \mathrm{ml}$ of trichloroacetic acid (TCA). Serum Alanine Transaminase (ALT), Aspartate Transaminase (AST), alkaline phosphatase (ALP), albumin and total serum bilirubin were analyzed in Dijlah university laboratory by using GENEX Chem-S1 semi-auto biochemical analyzer, USA.

\subsection{Statistical Analysis}

Values are expressed as the mean $\pm \mathrm{S}$. E. M; independenttest was used to compare means. The correlation between blood lead levels and duration of exposure were evaluated with Pearson's correlation. Statistical analyses were conducted with SPSS for Windows, version 21.0. Any $\mathrm{P}$ values less than 0.05 were considered statistically significant.

\section{Results}

\subsection{Demographic}

Table 1 shows that no significant $(p>0.05)$ differences in the mean \pm S. E. M age of lead-exposed subjects of gasoline station workers and brick kiln workers (36.06 \pm 1.72 and $30.24 \pm 1.8 \mathrm{yrs}$, in order) as compared to the control group (32.1 $\pm 1.99 \mathrm{yrs})$, while the age of battery manufacture worker $(45 \pm 0.85 \mathrm{yrs})$ were significantly $(p<0.01)$ higher than that of other groups.

The mean \pm S. E. M duration of work for gasoline station, battery manufacture and brick kiln workers were $(9.71 \pm 0.93$, $20.83 \pm 1.53$ and $11.45 \pm 0.98$ years, respectively as shown in table 1).

Table 1. Age and duration of lead exposed group and control group.

\begin{tabular}{lll}
\hline Groups & Age (years) & Duration of work (years) \\
\hline Gasoline station worker $(\mathrm{n}=28)$ & $36.06 \pm 1.72$ & $9.71 \pm 0.93$ \\
Battery manufacture worker $(\mathrm{n}=31)$ & $45 \pm 0.85^{* *}$ & $20.83 \pm 1.7$ \\
Brick kiln worker $(\mathrm{n}=33)$ & $30.24 \pm 1.8$ & $11.45 \pm 0.98$ \\
Control $(\mathrm{n}=18)$ & $32.1 \pm 1.99$ & - \\
\hline
\end{tabular}

Values are presented as mean \pm S. E. M; $n=$ number of subjects

** significantly different compared to control group $(\mathrm{P}<0.01)$.

\subsection{Blood Lead Level}

The results of the present study ( Table 2 and Figure 1) was revealed a significant increase $(\mathrm{p}<0.001)$ in the mean BLL values among gasoline station workers (24.96 \pm $0.76 \mu \mathrm{g} / \mathrm{dL})$, battery manufacture workers $(24.7 \pm 0.77 \mu \mathrm{g} / \mathrm{dL})$ and brick kiln workers $(24.63 \pm 0.81 \mu \mathrm{g} / \mathrm{dL})$, as compared to mean values of control group $(18.88 \pm 0.51 \mu \mathrm{g} / \mathrm{dL})$.

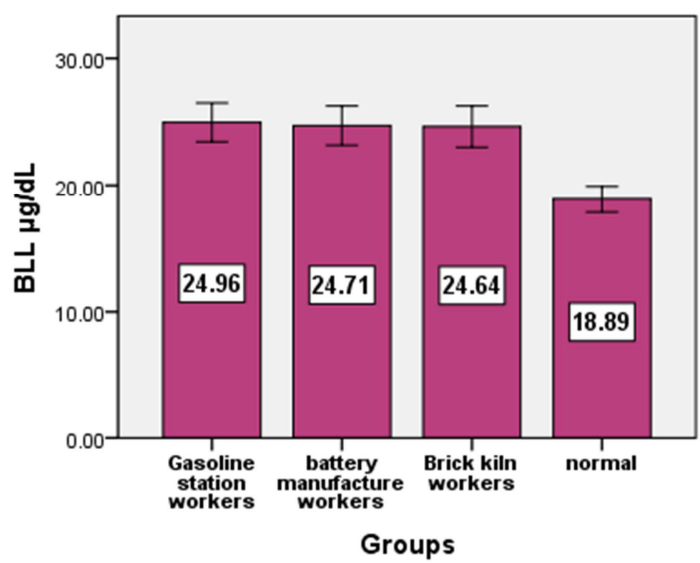

Figure 1. Mean BLL values between workers and control group
Table 2. Distribution of BLL values for studied groups.

\begin{tabular}{ll}
\hline Groups & Blood lead levels $(\boldsymbol{\mu g} / \mathbf{d l})$ \\
\hline Gasoline station worker $(\mathrm{n}=28)$ & $24.96 \pm 0.76^{* * *}$ \\
Battery manufacture worker $(\mathrm{n}=31)$ & $24.7 \pm 0.77 * * *$ \\
Brick kiln worker $(\mathrm{n}=33)$ & $24.63 \pm 0.81 * * *$ \\
Control $(\mathrm{n}=18)$ & $18.88 \pm 0.51$ \\
\hline
\end{tabular}

Values are presented as mean \pm S. E. M; $n=$ number of subjects

*** significantly different compared to control group $(\mathrm{P}<0.001)$.

\subsection{Liver Function Tests}

Table 3 showed that the activity of serum ALT was significantly $(p<0.05)$ elevated in gasoline station, battery and brick kiln workers as compared to the control group, while no significant increase of AST in workers versus control groups. On the other hand, serum alkaline phosphatase activity was exhibit significant $(\mathrm{p}<0.01)$ elevation in all worker groups as compares to the control group, no significant change was recorded in other liver biomarkers; serum AST activity, albumin and bilirubin level. Labor duration and exposure of workers to lead in relation to their BLL values are represented in figure 2. 
Table 3. Effect of lead exposure of workers groups on liver function markers.

\begin{tabular}{llllll}
\hline Liver function test & & & & \\
\hline Groups & Albumin $(\mathbf{g} / \mathbf{l})$ & ALT $(\mathbf{I U} / \mathbf{L})$ & AST (IU/L) & ALP (IU/L) & TSB (mg/dl) \\
\hline Gasoline station worker $(\mathrm{n}=28)$ & $65.94 \pm 3.38$ & $14.55 \pm 1.03^{*}$ & $10.32 \pm 1.3$ & $21.94 \pm 1.79^{* *}$ & $1.3 \pm 0.13$ \\
Battery worker ( $=31)$ & $63.35 \pm 3.28$ & $15.1 \pm 0.88^{*}$ & $11.83 \pm 1.2$ & $37.89 \pm 7.5^{* *}$ & $1.6 \pm 0.25$ \\
Brick kiln worker (n=33) & $65.12 \pm 2.17$ & $14.89 \pm 1.07^{*}$ & $9.06 \pm 1.45$ & $49.8 \pm 7.12^{* *}$ & $1.33 \pm 0.12$ \\
Control (n=18) & $58.7 \pm 3.46$ & $11.55 \pm 0.97$ & $11.05 \pm 0 . .99$ & $18.25 \pm 3.17$ & $1.3 \pm 0.15$ \\
\hline
\end{tabular}

Values are presented as mean \pm S. E. M; $n=$ number of subjects;

* Significantly different compared to control group $(\mathrm{P}<0.05)$.

** Significantly different compared to control group $(\mathrm{P}<0.01)$.

*** Significantly different compared to control group $(\mathrm{P}<0.001)$.

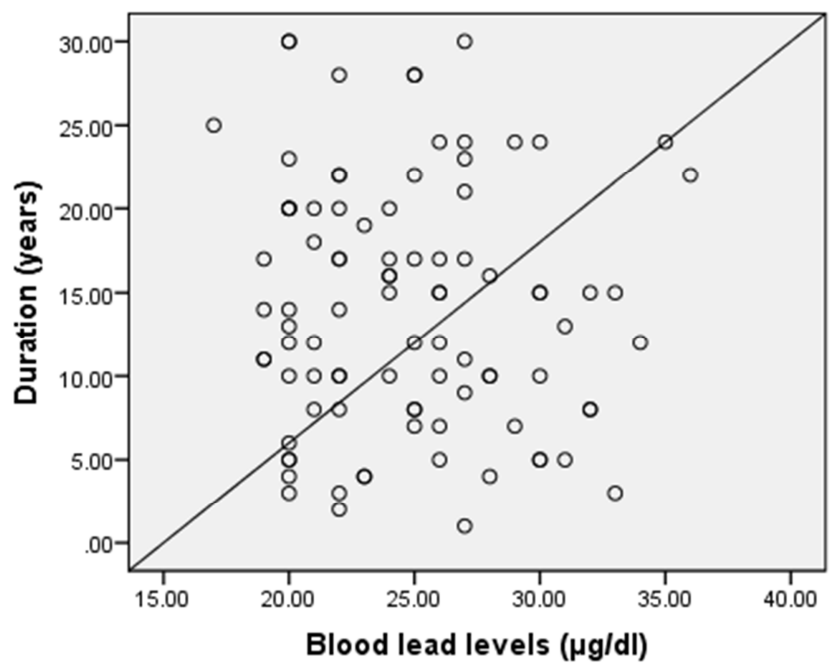

Figure 2. Scatter graph for correlation between BLL and duration of work for worker groups.

\section{Discussion}

Lead particles and lead oxide released into the environment may cause pollution and lead poisoning of workers in various industries. Poisoning can result from lack of safety measures such as facemasks, protective cloths, gloves or not adopting the standard criteria. These factors render workers more susceptible to toxic efforts of fumes. [7]. In this study the higher the mean age of batteries manufacturer workers as compared with other groups maybe due to longer duration exposure as shown in table 1 .

Significant elevation $(\mathrm{p}<0.001)$ in the blood lead levels of all workers in workers as compared to the control was because of long duration exposure to lead fumes.

The result of this study is coincided with Zuhir [8]" and "Saeed [9]", where blood lead level is ranged between 20 $88 \mu \mathrm{g} / \mathrm{dl}$ and $32.2 \mu \mathrm{g} / \mathrm{dl}$ respectively and the corresponding values for the control was $12.4 \mu \mathrm{g} / \mathrm{dl}$. In UAS and Germany the mean BLL of unexposed groups were 10 and $15 \mu \mathrm{g} / \mathrm{dl}$ in order. The elevated BLL $(18.88 \mu \mathrm{g} / \mathrm{dl})$ of unexposed group (control) in this study as compared to the result of other studies maybe attributed to the higher environmental pollution with subsequent BLL elevation. However, in split of the fact that the biological standard of BLL ranged between $7-22 \mu \mathrm{g} / \mathrm{dl}$ as reported by NIOSH [10], plant and soil contamination with lead was confirmed in an area away from kilns. Elevated lead level (92-214 $\left.\mathrm{mg} \mathrm{kg}^{-1}\right)$ was found near brick kilns are reported by Sikder et al. 2015 [11].

The activity of serum ALT is significantly increased $(p<0.05)$ in all worker groups in this study, while not recorded any significant change in AST enzyme for all workers as compared to the control subjects. ALT is present in different sorts of soft tissues but is most commonly related with the liver and ALT is a useful biomarkers for hepatocellular injury [12]. AST is mainly present in the mitochondria and the small amount of AST is present in the cytoplasm, therefore, when an injured hepatocellular cytosolic AST become visible in the blood but mitochondrial AST persists in the core regions of an injured cell [13]. Ţincu et al. shows that the mean AST value were $23.5 \pm 2.2 \mathrm{U} / \mathrm{L}$ in a group exposed to lead and $24 \pm 4.2 \mathrm{U} / \mathrm{L}$ in the control group [14].

Accumulation of lead mostly in soft tissues, liver and bones after exposure and bounds to red blood cell and toxic effect of lead is induce of oxidative stress (overproduction of reactive oxygen species), which can result in peroxidation damage to hepatic cell membrane and release liver enzymes in serum [15-17].

Increased activity of ALT level in occupational group may be due to increased lead level in blood because of long duration of workers and recently similar results are also reported [18-19]. The activity of serum alkaline phosphatase increased in workers group as compared to control subject. this finding is consistent with National Referral Centre for Lead Poisoning in India [20]. On the other hand, no significant alteration in serum albumin and total serum bilirubin was observed in the workers group as compared to the control subject. however, albumin was apparently elevated in the workers of all groups, but this elevation was not significant as compared to the control.

\section{Conclusion}

The exposure of the Iraqi workers either in Gasoline stations, Battery manufacturer or Brick Kiln to lead, directly or indirectly were the main reasons for elevated lead level in the blood of workers $(\approx 25 \mu \mathrm{g} / \mathrm{dl})$. In spite of the fact that in adults, lead blood level up to $(5-11 \mu \mathrm{g} / \mathrm{dl})$ was considered normal, but in this study the non-exposure subject (control) showed an elevated lead level $(\approx 19 \mu \mathrm{g} / \mathrm{dl})$ and this may attributed to the dramatically increase in the number of motor 
vehicle with the consequence of lead emission from leaded petrol exhaust which may contributed to the air pollution, as well as the absence of official legislations in environmental protections.

Moreover some workers clarified that Sub-chronic exposure to lead caused a significant decrease in serum albumin and total serum bilirubin, while in this study no significant differences were recorded in these parameters, because chronic exposure to lead particles may created a sort of balance between the high lead levels, which catalyzes oxidative reactions (generation of reactive species) and albumin the major and predominant antioxidant in the serum.

The result of this study was confirmed that chronic exposure (a sort of oxidative stress) of workers to lead vapors by absorption through skin and hair, inhalation, ingestion and contamination of their clothing, food and drinking water caused hepatic toxicity manifested by significant elevation in ALT and ALP levels in the blood.

\section{References}

[1] Agency for Toxic Substances and Disease Registry. (ATSDR) Atlanta, Georgia, USA: US Department of health and human services. Draft toxicological profile for lead. ATSDR 2005; 102-225.

[2] Papp JF, Bray EL, Edelstein DL, Fenton MD, Guberman DE, Hedrick JB, Jorgenson J D, Kuck PH, Shedd KB and Tolcin AC. Factors that influence the price of $\mathrm{Al}, \mathrm{Cd}, \mathrm{Co}, \mathrm{Cu}, \mathrm{Fe}, \mathrm{Ni}$, $\mathrm{Pb}$, Rare Earth Elements, and Zn: U. S. Geological Survey Open-File Report 2008; 1356, p. 61.

[3] Se Hc, Seon BY, Jae WL, Duk JL. What caused hemolytic anaemia and colicky abdominal pain? Lead! Korean J Intern Med 2013; 28: 504: 6 .

[4] QASIM, Saeeda Fouzia; BALOCH, Malka. Lead toxicity in battery workers. J Coll Physicians Surg Pak, 2014, 24.11 Suppl 3: S284-286.

[5] Onyeneke, E. C., \& Omokaro, E. U. (2016). Effect of occupational exposure to lead on liver function parameters. Int. J. Pharm. Med. Sci, 6, 15-19.

[6] Green, R. M.; Flamm, S. AGA technical review on the evaluation of liver chemistry tests. Gastroenterology 2002, 123, 1367-1384.

[7] Mohammed, Sirwan M. "Hematological, Biochemical and Blood Lead Level Profile among Gasoline Exposed Station Workers in Sulaimaniya City." ARO-The Scientific Journal of Koya University2.1 (2016): 6-11.
[8] Zuhir, O. 2007. Determination of Blood Lead Levels in Traffic- and Gasoline Exposed Professionals in Khartoum State- Sudan, M. Sc. thesis, O. I. U. Khartoum, Sudan, pp. 2240 .

[9] Saeed, H S, Abdelmonem M. Abdellah, Fatima Altayib Alasha Abdalla, Aghaei afshar Abbas, F. Adam and Nafisa A. Elgazali. "Biochemical Effects of Lead Toxicity on Serum Total Protein, Albumin and Globulin Levels in Occupationally Exposed Workers in Major Sudanese Cities.” (2017).

[10] NIOSH (National Institute for Occupational Safety and Health). 1978. 'criteria for a recommended standard occupational exposure to Inorganic lead -Revised Criteria' Cincinnati, DHEW (NIOSH) publication No. 78, pp 158.

[11] SIKDER, Abdul Halim Farhad, et al. Lead and cadmium accumulation in nearby brick kiln Agri-environmental ecosystems. Bangladesh Journal of Scientific Research, 2015, 28.1: 51-59.

[12] Kim YJ: Interpretation of liver function tests. Korean J Gastroenterol 2008, 51 (4): 219-224. Korean.

[13] Kamiike W, Fujikawa M, Sumimura J, Miyata M, Kawashima Y, Wada H, TAgawa K: Differential patterns of leakage of cytosolic and mitochondrial enzymes. Clin Chim Acta 1989, 185: 265-270.

[14] ȚINCU, RADU CIPRIAN, et al. Biochemical parameters changes induced by lead exposure. FARMACIA 2016, 64: 2.

[15] Dongre NN, Suryakar AN, Patil AJ, Rathi DB. Occupational lead exposure in automobile workers in North Karnataka (India): effect on liver and kidney functions. Al Ameen J Med Sci 2010; 3 (4): 284-92.

[16] Mudipalli A. Lead hepatotoxicity \& potential health effects. Indian J Med Res 2007 Dec 1; 126 (6): 518.

[17] Aziz II, Al Agha SZ. Hematological and Biochemical Studies for Gasoline Toxicity Among Gasoline Workers In Gaza Strip. AlAgsa Univ. J 2006; 10: 41-55.

[18] Bislimi K, Behluli A, Halili J, Mazreku I, Osmani F, Fetahu $\mathrm{SH}$, Halili F. Some Biochemical Parameters and Level of Concentration of Lead in Blood of Battery Factory Workers in Mitrovica. 13th SGEM Geo Conference on Ecology, Economics, Education And Legislation, www.sgem.org, SGEM2013 Conference Proceedings, 2013; 1: 891-896.

[19] Akram Umran Hasan, Measurement of Some Biochemical Markers Level in Blood of Mercury Exposure Workers, [Ph. D Thesis]. College of Science: Baghdad University; 2013.

[20] Aryapu Raviraja, Gaja Narayanamurthy Vishal Babu, Anita Raghuveer Bijoor, Geraldine Menezes, Thuppil Venkatesh. Lead Toxicity in a Family as a Result of Occupational Exposure. Arh Hig Rada Toksikol 2008; 59: 127-133. 